\title{
Molecular characterization and identification of members of the Anopheles subpictus complex in Sri Lanka
}

\author{
Sinnathamby N Surendran ${ }^{1,2^{*}}$, Devojit K Sarma ${ }^{2,3}$, Pavilupillai J Jude ${ }^{1}$, Petri Kemppainen², \\ Nadarajah Kanthakumaran ${ }^{1}$, Kanapathy Gajapathy ${ }^{1}$, Lalanthika BS Peiris ${ }^{4}$, Ranjan Ramasamy ${ }^{1}$ \\ and Catherine Walton ${ }^{2 *}$
}

\begin{abstract}
Background: Anopheles subpictus sensu lato is a major malaria vector in South and Southeast Asia. Based initially on polytene chromosome inversion polymorphism, and subsequently on morphological characterization, four sibling species A-D were reported from India. The present study uses molecular methods to further characterize and identify sibling species in Sri Lanka.

Methods: Mosquitoes from Sri Lanka were morphologically identified to species and sequenced for the ribosomal internal transcribed spacer-2 (ITS2) and the mitochondrial cytochrome c oxidase subunit-I (COI) genes. These sequences, together with others from GenBank, were used to construct phylogenetic trees and parsimony haplotype networks and to test for genetic population structure.

Results: Both ITS2 and COI sequences revealed two divergent clades indicating that the Subpictus complex in Sri Lanka is composed of two genetically distinct species that correspond to species A and species B from India. Phylogenetic analysis showed that species A and species B do not form a monophyletic clade but instead share genetic similarity with Anopheles vagus and Anopheles sundaicus s.l., respectively. An allele specific identification method based on ITS2 variation was developed for the reliable identification of species A and B in Sri Lanka.
\end{abstract}

Conclusion: Further multidisciplinary studies are needed to establish the species status of all chromosomal forms in the Subpictus complex. This study emphasizes the difficulties in using morphological characters for species identification in An. subpictus s.l. in Sri Lanka and demonstrates the utility of an allele specific identification method that can be used to characterize the differential bio-ecological traits of species A and B in Sri Lanka.

Keywords: Anopheles subpictus, Anopheles sundaicus, Cytochrome c oxidase subunit-I, ITS2, Malaria, Sibling species, Sri Lanka

\section{Background}

Anopheles subpictus sensu lato has a very wide distribution in the Oriental and Australasian regions ranging through Pakistan, India, Sri Lanka, Bangladesh, Myanmar, Thailand, Cambodia, Vietnam, Malaysia, Indonesia, Timor-Leste and Papua New Guinea [1,2]. The taxon exists as a species complex and is a primary vector of malaria in many

\footnotetext{
* Correspondence: noble@jfn.ac.lk; catherine.walton@manchester.ac.uk 'Department of Zoology, Faculty of Science, University of Jaffna, Jaffna 40000, Sri Lanka

${ }^{2}$ Faculty of Life Sciences, University of Manchester, Oxford Road, Manchester M13 9PT, UK

Full list of author information is available at the end of the article
}

Southeast (SE) Asian countries and is regarded as a secondary vector in Sri Lanka [2-5]. In India, An. subpictus s.l. is reported to exist as a species complex comprising four sibling species viz. A, B, C and D [6,7]. Each species is associated with a specific combination of two polytene chromosome inversions viz. $\mathrm{A}=\mathrm{X}+{ }^{\mathrm{a}}+{ }^{\mathrm{b}} ; \mathrm{B}=\mathrm{Xab} ; \mathrm{C}=\mathrm{Xa}$ $+{ }^{b} ; \mathrm{D}=\mathrm{X}+{ }^{\mathrm{a}} \mathrm{b}$, and stage specific morphometric characteristics such as number of egg ridges, number of branches in the $4 \mathrm{M}$ setae of larvae, and ornamentation of adult palpi [6]. Based on the single inversion $\left(X+{ }^{a} / X a\right)$ on the $X$ chromosome, the presence of species $\mathrm{A}$ and $\mathrm{B}$ was reported in Sri Lanka [8]. Although no other polytene chromosomal

\section{Biomed Central}


studies looking at the two X chromosome inversions have yet been conducted in Sri Lanka for this taxon, the presence of morphometric characteristics corresponding to the Indian sibling species, led to the reporting of all four (A-D) sibling species from Sri Lanka $[5,9,10]$.

Like any species complex, members of the Subpictus complex show differential bio-ecological traits such as salinity tolerance, susceptibility to common insecticides and vectorial capacity $[5,7,11,12]$. The development of appropriate vector control strategies when dealing with species complexes, therefore, requires reliable molecular diagnostic tools and an understanding of inter and intraspecific genetic diversity of vector populations [13]. In India, species B is predominant and is a vector in coastal areas of Southern India whereas species $\mathrm{A}, \mathrm{C}$ and $\mathrm{D}$ are predominant in inland areas [1,7] with species A being a vector in West Bengal of India [14]. The members of the Subpictus complex in Sri Lanka also differ in bio-ecological properties $[9,11,12]$ but the full characterization of these requires the development of reliable species diagnostic tools.

The simplest and least expensive way to identify malaria vectors in the field is morphologically. However, there are limitations with using morphological characteristics alone to differentiate sympatric sibling species of anopheline species complexes and closely related taxa [15]. In general, DNA-based methods provide more definitive identification and have an advantage over classical morphological and cytogenetic methods because of their reliability, precision, ease of handling and processing, and their applicability to all mosquito life stages [16]. An excellent species diagnostic molecular marker is the internal transcribed spacer 2 (ITS2) of the ribosomal DNA (rDNA) as its sequence is likely to vary even between closely related species [17].

Morphological descriptions have been given for the four species of the Subpictus complex in India [6]. However, when these diagnostic characters have been applied in Sri Lanka conflicts among putatively diagnostic characters (ornamentation of wing and palpi, number of egg ridges and number of branches of 4 M larval setae) have been observed leading to uncertainty in species identification [18]. Consequently, the present study was designed to determine the taxonomic status of the species complex in Sri Lanka by genetic characterization of the morphologically identified sibling species using ITS2 and the cytochrome $c$ oxidase subunit-I (COI) of mitochondrial DNA (mtDNA). The taxonomic designation and ITS2 differentiation among species were subsequently used to develop a DNA based diagnostic assay for the members of the Subpictus complex in Sri Lanka.

\section{Methods}

\section{Study sites, sample collection and sibling species} identification

Mosquito samples (adult and larvae) were collected from nine different localities in Sri Lanka (Additional file 1: Table S1, Figure 1). Adult anopheline mosquitoes were collected during the period of February 2011 to July 2012 using cattle baited hut (CBHC), cattle baited net (CBNC) and hand collection ( $\mathrm{HC}$ ) (using a mouth aspirator) techniques. Larvae were also collected between November 2011 and June 2012 using an $8 \mathrm{~cm}$ diameter and $240 \mathrm{ml}$ capacity dipper as described previously [11]. Salinity of water samples was measured using a salinometer (Atago, Japan). The collected adults and larvae were brought to the Zoology Laboratory of the University of Jaffna and identified as An. subpictus s.l. using published keys [19-21].

Blood-fed females were maintained individually and single female $F_{1}$ progenies were raised as described previously [11]. The females laying eggs were putatively identified as sibling species A, B, C or D based on the morphological character reported to distinguish these taxa in India, the number of ridges in the egg floats i.e. species A, 31-36; species B, 16-20; species C, 25-29 and species D, 21-24 [6]. Five to ten eggs from each female were placed on a clean microscopic slide and the number of ridges on floats counted under a light microscope ( $x 4$, Olympus). Collected larvae were maintained as described previously [11]. Putative sibling species status of the adults that emerged from the collected larvae was determined using published morphometric characteristics (ornamentation of palpi) for the Subpictus complex in India [6]. Any deviation(s) from reported morphological descriptions were noted and the samples were preserved individually in $0.5 \mathrm{ml}$ Eppendorf tubes with silica gel for later molecular characterization.

\section{DNA extraction and amplification}

For DNA extraction, the TENS/phenol-chloroform procedure of Sambrook \& Russell [22] was modified by adding the use of Phase Lock Gel (5 Prime) tubes and Qiaex II beads (Qiagen). Phase Lock Gel increases purity and yield of the extracted DNA by forming a tight layer between the aqueous and organic phases while completely trapping the interface. Qiaex II bead suspension, which efficiently binds DNA at $\mathrm{pH}<7$, was added before ethanol precipitation to minimize the risk of losing the DNA pellet when decanting the ethanol.

Individual mosquitoes were homogenized in $300 \mu \mathrm{l}$ TENS buffer [22] with $6 \mu \mathrm{l}$ proteinase-K $(10 \mathrm{mg} / \mu \mathrm{l}$, Merck Chemicals Ltd) and incubated for four hours at $55^{\circ} \mathrm{C}$. The homogenate was transferred to pre-spun $2 \mathrm{ml}$ Phase Lock Gel Heavy tubes (5 Prime) and $300 \mu \mathrm{l}$ of phenol:chloroform:isoamyl alcohol, 25:24:1, $\mathrm{pH}=8$ 


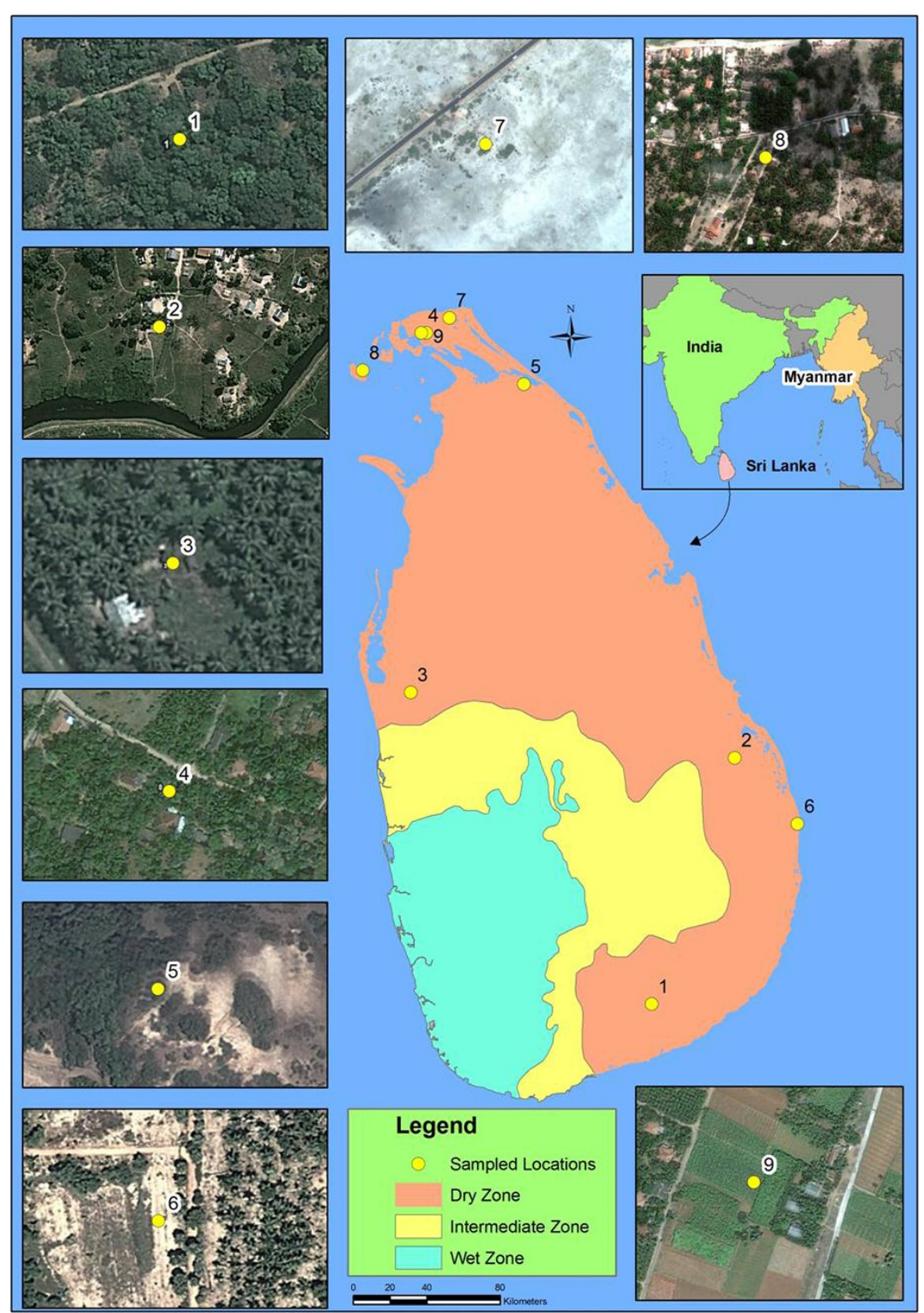

Figure 1 Map showing the adult and larval collections sites and the climatic zones (dry, intermediate and wet zones classified based on annual rain fall) of Sri Lanka. (1). Ranawarunawa, (2). Unnichchai, (3). Thonikkal, (4). Chunnakam, (5). Puliyampokkanai, (6). Kalmunai, (7). Sarasalai, (8). Delft island and (9). Suthumalai.

(Sigma-Aldrich) was added prior to centrifugation at $13000 \mathrm{rpm}$ for $3 \mathrm{~min}$. After adding $400 \mu \mathrm{l}$ of chloroform: isoamyl alcohol, 24:1 (Sigma-Aldrich) the tube was centrifuged for $3 \mathrm{~min}$ at $13000 \mathrm{rpm}$. The aqueous phase was transferred to a new tube containing $750 \mu \mathrm{l}$ of $100 \%$ $\mathrm{EtOH}$ and $5 \mu \mathrm{l}$ of Qiaex II suspension (Qiagen). The tube was kept on ice for 10 min and spun at $13000 \mathrm{rpm}$ for $45 \mathrm{~min}$ at $4^{\circ} \mathrm{C}$. After decanting the $\mathrm{EtOH}$ (without disrupting the Qiaex II/DNA pellet at the bottom of the tube), $50 \mu \mathrm{l}$ of 1:1 mixture of MQ water (Millipore) and QX1 buffer (Qiagen) was added and kept at room temperature for $3 \mathrm{~min}$. Another $150 \mu \mathrm{l}$ of the same mixture was added and kept for $7 \mathrm{~min}$ with gentle mixing every 1-2 min. The tube was centrifuged at $13,000 \mathrm{rpm}$ for $30 \mathrm{sec}$ to pellet the Qiaex II/DNA pellet. Following removal of the supernatant, the Qiaex II/DNA pellet was 
washed twice with $500 \mu \mathrm{l}$ of Buffer PE (wash buffer, Qiagen) according to the Qiaex II protocol. The sample was then centrifuged at $13000 \mathrm{rpm}$ for $30 \mathrm{sec}$ and all traces of supernatant removed, after which the pellet was air-dried for 10-20 min. DNA was eluted from the beads by adding $22 \mu \mathrm{l}$ of Elution Buffer (EB buffer, Qiagen) for $10 \mathrm{~min}$ at $50^{\circ} \mathrm{C}$. The sample was spun at $13000 \mathrm{rpm}$ for $30 \mathrm{sec}$ and the DNA solution pipetted out. This was repeated again with $20 \mu$ l of EB buffer to get a total elution volume of $40 \mu$ l (typically $2 \mu \mathrm{l}$ was retained by the Qiaex II beads). The extracted DNA was refrigerated until further analysis.

The ITS2 region of the rDNA of identified sibling species was amplified using the $5.8 \mathrm{~S}$ forward and $28 \mathrm{~S}$ reverse primers [16] and the COI region of the mtDNA was amplified using primers C1-J-1718 and C1-N-2191 [23]. For each amplification, PCR reactions were performed in a $25 \mu \mathrm{l}$ volume that included $1 \mu \mathrm{l}$ of DNA, each primer at $0.5 \mu \mathrm{M}, 2.5 \mathrm{mM} \mathrm{MgCl}_{2}, 0.2 \mathrm{mM} \mathrm{dNTP}$ mix and 1.25 U Taq DNA polymerase in 1x PCR buffer (Bioline, UK). The samples were heated at $94^{\circ} \mathrm{C}$ for $4 \mathrm{~min}$ before 35 cycles of amplification at $94^{\circ} \mathrm{C}$ for $30 \mathrm{sec}, 53^{\circ} \mathrm{C}(\mathrm{ITS} 2) / 57^{\circ} \mathrm{C}(\mathrm{COI})$, and $72^{\circ} \mathrm{C}$ for $45 \mathrm{sec}$ followed by a final extension at $72^{\circ} \mathrm{C}$ for $7 \mathrm{~min}$. The PCR products were purified using GenElute ${ }^{\text {тм }}$ PCR Clean-UP Kit (Sigma-Aldrich). Purified PCR products of ITS2 and COI were sequenced in both directions using the Big Dye Terminator V3.1 Cycle Sequencing Kit (Applied Biosystems, USA) on an ABI 3730 automatic sequencer (PE Applied Biosystems, Foster City, CA, USA) at the University of Manchester core sequencing facility. Sequence chromatograms were manually edited in Geneious 4.8.5 [24] and compared with sequence data available in GenBank using BLASTn search.

\section{Sequence alignment and reconstruction of phylogenetic trees}

All generated ITS2 and COI sequences were aligned along with other sequences for An. subpictus s.l. and Anopheles sundaicus s.l. retrieved from GenBank using ClustalW2in MEGA, version 5 [25]. Phylogenetic relationships among members of the Subpictus complex from Cambodia, India, Myanmar, Sri Lanka, Thailand, and Vietnam along with An. sundaicus s.l. from India, Malaysia (Borneo), Myanmar and Timor-Leste were inferred using the maximum likelihood (ML) method. Anopheles sundaicus is a species complex and based on known geographical distributions $A n$. sundaicus from Borneo is expected to be An. sundaicus s.s. and $A n$. sundaicus from India is expected to be species D [2] but the species identity of An. sundaicus in Myanmar and Timor-Leste is unknown. Therefore, collectively all the samples are referred to as An. sundaicus s.l. The substitution model selection was also performed in MEGA5 based on the lowest Bayesian Information Criterion (BIC) value. The Jukes-Cantor model for the ITS2 and Tamura 3-parameter with Gamma distribution model for the COI sequence data set were selected. Bootstrap [26] supports were based on 1000 re-sampled datasets using MEGA, version 5. As Anopheles vagus has also been reported to be genetically similar to An. subpictus s.l. and An. sundaicus s.l. [27], GenBank sequences of $A n$. vagus were also included for comparison; ITS2 sequences from China (FJ457631) and India (JN710015) and COI sequences from India (AY834247) and Indonesia (GQ284816).

\section{Development of an allele specific PCR assay}

In order to distinguish sibling species $A$ and $B$ of the Subpictus complex in Sri Lanka an allele specific PCR assay was developed that utilized a common forward primer SubF (5'-3': ACTGCAGGACACATGAACACCG) and species-specific reverse primers SubA (5'-3': GCTTGTTGTCGAACCGTGCGAT) and SubB (5'-3': ATCCGGTTGATACAGGACGCAC). The diagnostic size of the PCR product for species A is $\sim 300$ bp while that for species $B$ is $\sim 400 \mathrm{bp}$. The PCR reactions were performed in $25 \mu \mathrm{l}$ volumes. Each reaction mix included $1 \mu \mathrm{l}$ of DNA, each primer at $0.5 \mu \mathrm{M}, 2.5 \mathrm{mM} \mathrm{MgCl}_{2}$, $0.2 \mathrm{mM}$ dNTP mix and 1.25 U Taq DNApolymerase in 1x PCR buffer (Bioline, UK). The samples were heated at $94^{\circ} \mathrm{C}$ for $4 \mathrm{~min}$ before 30 cycles of amplification at $94^{\circ} \mathrm{C}$ for $30 \mathrm{sec}, 56^{\circ} \mathrm{C}$ for $30 \mathrm{sec}$, and $72^{\circ} \mathrm{C}$ for $30 \mathrm{sec}$ followed by a final extension at $72^{\circ} \mathrm{C}$ for $7 \mathrm{~min}$. The amplified PCR products were visualized by electrophoresis in $1.5 \%$ agarose gels stained with GelRed ${ }^{\mathrm{TM}}$ nucleic acid gel stain (Biotium, Inc., USA).

\section{DNA sequence analysis and population genetic structure based on $\mathrm{COI}$ sequences}

The COI sequences of Sri Lankan samples along with available sequences for $A n$. subpictus of India and Myanmar in the NCBI GenBank were aligned in MEGA, version 5 [25]. Genetic information such as number of haplotypes, segregating sites, haplotype diversity and nucleotide diversity were estimated using DnaSP 5.10 [28].

ModelTest [29] was used to determine the best model of nucleotide substitution. The AIC (hierarchical likelihood tests and Akaike Information Criteria) revealed K81uf (Unequal-frequency Kimura 3-parameter plus Gamma) as the best model $(\mathrm{LnL}=-1109.652080$; $\mathrm{AIC}=$ 2231.30416). However, in Arlequin 3.1 [30], the closest model of evolution (Tamura and Nei) was used [31]. Pairwise $\mathrm{F}_{\mathrm{ST}}$ values were estimated in Arlequin 3.1 [30] and their significance was tested by 1,000 permutations. A statistical parsimony based haplotype network for the populations was created using TCS v1.21 [32]. 


\section{Results}

\section{Morphological identification of collected samples}

Based on the current morphological descriptions of $A n$. subpictus in India [6] all four (A-D) sibling species of the An. subpictus complex were found among the samples collected in Sri Lanka. The collection technique, morphometric characters used for identification of the sibling species collected and number of species identified based on morphometric characteristics are given in Additional file 1: Table S1. From across Sri Lanka a total of 887 specimens were processed resulting in 26 individuals identified as species A, 378 as species B, 394 as species $C$ and 89 as species D. Based on these identifications, species $\mathrm{A}, \mathrm{C}$ and $\mathrm{D}$ were predominant in inland localities and species B in coastal localities. Species B larvae were collected from breeding sites with salinity five to 12 parts per 1,000 (ppt). Deviations from the typical taxonomic (morphological) characteristics were observed in the samples identified as species B [18]. For example, the samples collected from coastal areas, namely Delft Island and Sarasali, were identified as species B based on number of egg ridges [6] but had pre-humeral long ornamentation in the wing that is not the taxonomic characteristic of An. subpictus but of other closely related species such as An. sundaicus and An. vagus [19]. Conversely, some specimens identified as species $B$ based on the number of egg ridges [6] and collected from
Suthumalai (an inland locality) had larvae with $4 \mathrm{M}$ single setae and pre-humeral long ornamentation in the wing characteristic of the recently reported Anopheles pseudosundaicus from South India [33].

\section{Phylogenetic analysis}

All four morphologically identified sibling species were sequenced for the rDNA ITS2 region ( $\mathrm{n}$, species $\mathrm{A}=2$; $\mathrm{B}=8 ; \mathrm{C}=5 ; \mathrm{D}=2$ ). The resulting 578 bp sequences were aligned with GenBank entries for An. subpictus from Cambodia, India, Myanmar, Sri Lanka, Thailand and Vietnam and An. sundaicus from India, Malaysia and Timor-Leste and sequences of An. vagus from India and China. The sequence dataset used for the final phylogenetic tree reconstruction was 387 bp in length. The resulting tree with sample names and corresponding GenBank accession numbers is given in Figure 2. The phylogenetic analysis revealed that all but two of the specimens from Sri Lanka identified morphologically as species B (including the specimens showing variations in the ornamentation of wing and palpi and number of branches in larval 4 M setae) clustered with GenBank entries for An. subpictus s.l. from Myanmar. This clade is referred to as the species B clade and from herein we consider individuals in this clade to belong to species $\mathrm{B}$ (see Discussion). However, two of the specimens morphologically identified as species B (based on number of

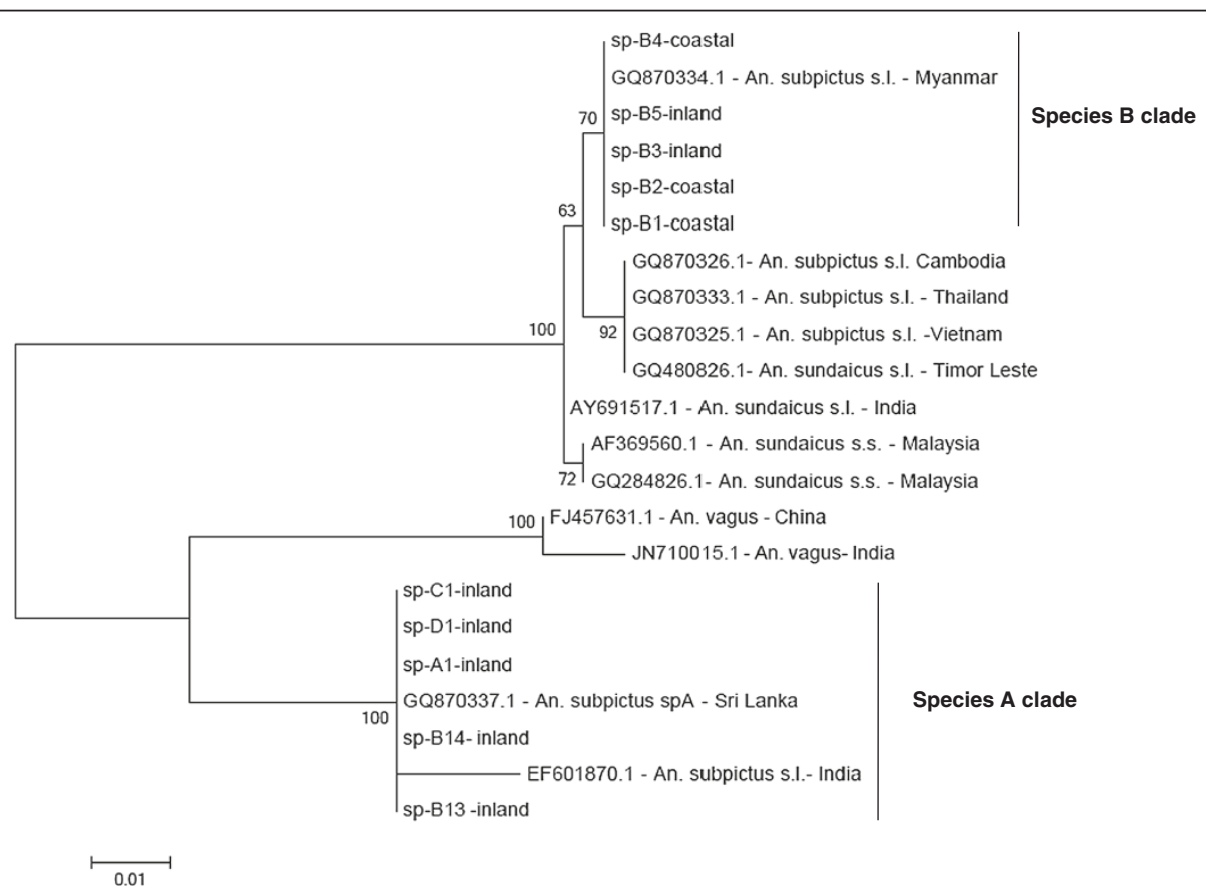

Figure 2 Phylogenetic analysis based on ITS2 sequences having 387 positions in the data set and constructed using the maximum likelihood method using the Jukes-Cantor model, showing bootstrap values $>\mathbf{5 0} \%$. Species A clade consists of all specimens belong to sibling species A and species B clade specimens belong to sibling species B. Specimens used for the analysis include morphologically identified species A, B, C and D of Sri Lanka (GenBank accession number: species A - KC191825; species B - KC191826) and other GenBank entries. The specimen's GenBank accession number is given along with the country it belongs to in the phylogenetic tree. 
egg ridges) and all other specimens identified as species A, C or D together formed a separate clade along with other GenBank entries of unidentified Indian samples and sequences from Sri Lanka designated as species A. This clade is referred to as the species A clade following earlier notation [34] and from herein individuals in this clade are considered to belong to species A (see Discussion). The corresponding ITS2 sequences for Sri Lanka species A (KC191825) and B (K191826) are deposited in GenBank. The ITS2 gene tree indicates that species A is closely related to An. vagus and distinct from species B which falls in a clade with other $A n$. subpictus from Southeast Asia and An. sundaicus s.l.

The $\sim 500$ bp COI sequences obtained for all four morphologically identified sibling species $(\mathrm{n}$, species $\mathrm{A}=$ $5 ; \mathrm{B}=11 ; \mathrm{C}=5 ; \mathrm{D}=3$ ) from Sri Lanka were aligned along with GenBank entries for An. subpictus from India including specimens identified as species $\mathrm{A}$ and $\mathrm{B}$ based on egg morphology [35] and Myanmar and $A n$. sundaicus s.l. from India, Malaysia and Myanmar. After trimming sequences to the same length, a dataset $423 \mathrm{bp}$ in length was used to reconstruct a phylogenetic tree (Figure 3). In the COI gene tree An. sundaicus, $A n$. vagus, An. subpictus A and An. subpictus B each formed distinct clades with similarly deep divergences. In concordance with the ITS2 gene tree, the COI tree suggested that An. subpictus A is most closely related to $A n$. vagus and An. subpictus B to An. sundiacus but the bootstrap support is too low to conclude this from this data alone. Despite this, the COI gene tree largely agreed with the ITS2 tree in revealing two distinct clades for An. subpictus with individuals falling into the species A or species B clade, entirely consistent with their location in the ITS2 gene tree.

\section{Genetic diversity and population genetic structure within species A and B}

Population genetic structure and genetic diversity was determined for all sequences within species $A$ and within species B, excluding sequences of species B in India which were too few in number to form a separate population. The two populations of species A from Sri Lanka and India had a pairwise $F_{\mathrm{ST}}$ value of 0.067 (p > 0.05 ) and the two populations of species $B$ from Sri Lanka and Myanmar had a pairwise $F_{\mathrm{ST}}$ value of -0.006 $(p>0.05)$. Given that sample numbers are relatively low it is possible that there is some weak population genetic structure that we have been unable to detect but these results nonetheless indicate that there is very little population substructure within these species over large geographical distances.

The number of segregating sites, haplotype diversity and genetic diversity estimates for the four populations of species A and B of the Subpictus complex are given in Additional file 2: Table S2. Corresponding haplotype sequences for Sri Lanka species A (KC191814 KC191817) and B (KC191818 - KC191824) are deposited in GenBank. There were a total of 25 haplotypes. In general, haplotype diversity and genetic diversity are high with the exception of the Sri Lankan population of species A, which has notably lower haplotype and nucleotide diversity. The statistical parsimony haplotype network created for the study populations is given in Figure 4. One haplotype (H2) was shared by populations of species B from Sri Lanka and Myanmar. Conversely, the high frequency (5/25) H8 haplotype was found only in species A from Sri Lanka, underlying the low genetic diversity of this population. Within each of the species, the haplotypes from different countries (Sri Lanka and India in clade A and Sri Lanka and Myanmar in clade B) were intermingled reflecting the lack of genetic population structure as detected by the AMOVA.

\section{Diagnostic allele specific PCR (AS-PCR) assay for species A and $B$ of the Subpictus complex}

As the molecular characterization revealed the presence of only two sibling species in Sri Lanka the AS-PCR assay was designed to distinguish only these two members. In the design of species specific primers, fixed base substitutions and indels between the ITS2 sequences were targeted and were mostly positioned at the 3 '-extreme end of the primer, where they have the greatest effect on inhibiting extension from mismatched primerDNA templates. At the same time, consideration was given to generate species-specific amplicons sufficiently different in size to be separated easily on an agarose gel. There is a common forward primer and species-specific reverse primers that were designed to amplify only from An. subpictus species A or An. subpictus species B and not to An. vagus or An. sundaicus. A panel of 22 samples collected from different localities and comprising different morphological forms of Subpictus complex in Sri Lanka were used for this assay. The assay clearly separated the specimens into two members of the Subpictus complex. There is no risk of false positives as this assay was unable to amplify products from Sri Lankan samples of An. vagus and as An. sundaicus is not present in Sri Lanka. All samples were found to produce the expected diagnostic lengths ( 300 bp for species $\mathrm{A}$ and $\sim 400 \mathrm{bp}$ for species B) in the AS-PCR assay (Figure 5).

\section{Discussion}

The present molecular characterization and population genetic analysis of two loci reveal that members of the Subpictus complex from Sri Lanka fall into two divergent clades. This indicates that the Subpictus complex in Sri Lanka is composed of two genetically distinct species instead of the four sibling species reported previously 


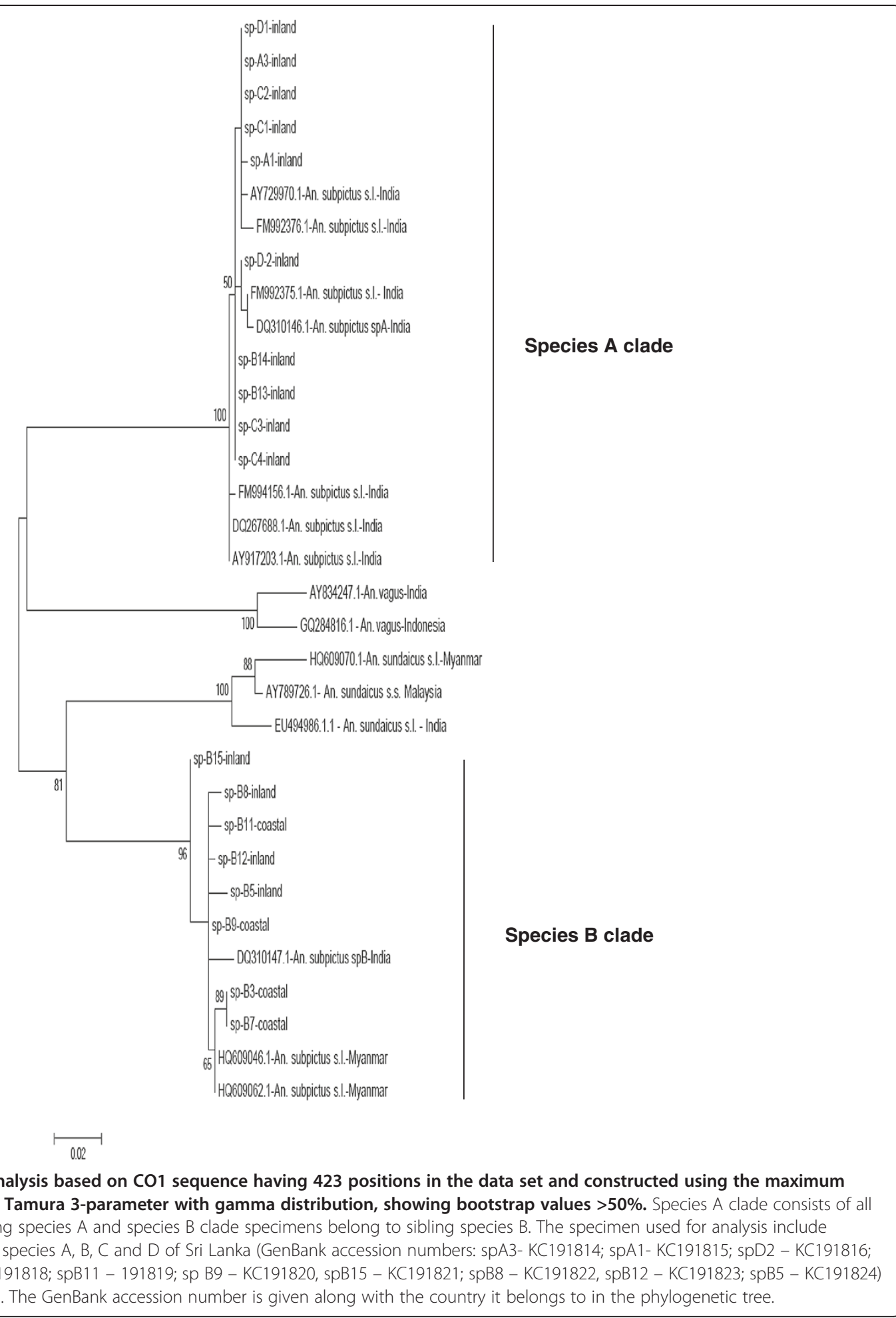

[5,9]. The populations forming the species A clade in the phylogenetic construction were tentatively designated as An. subpictus species $\mathrm{A}$, and the populations that formed the species B clade as An. subpictus species B since in the COI gene tree these clades contain specimens from India identified as species $\mathrm{A}$ and species $\mathrm{B}$, respectively.

The present study confirms earlier suspicions $[15,18]$ that the morphological-based identification reported for the Indian Subpictus complex [6] is not able to reliably 


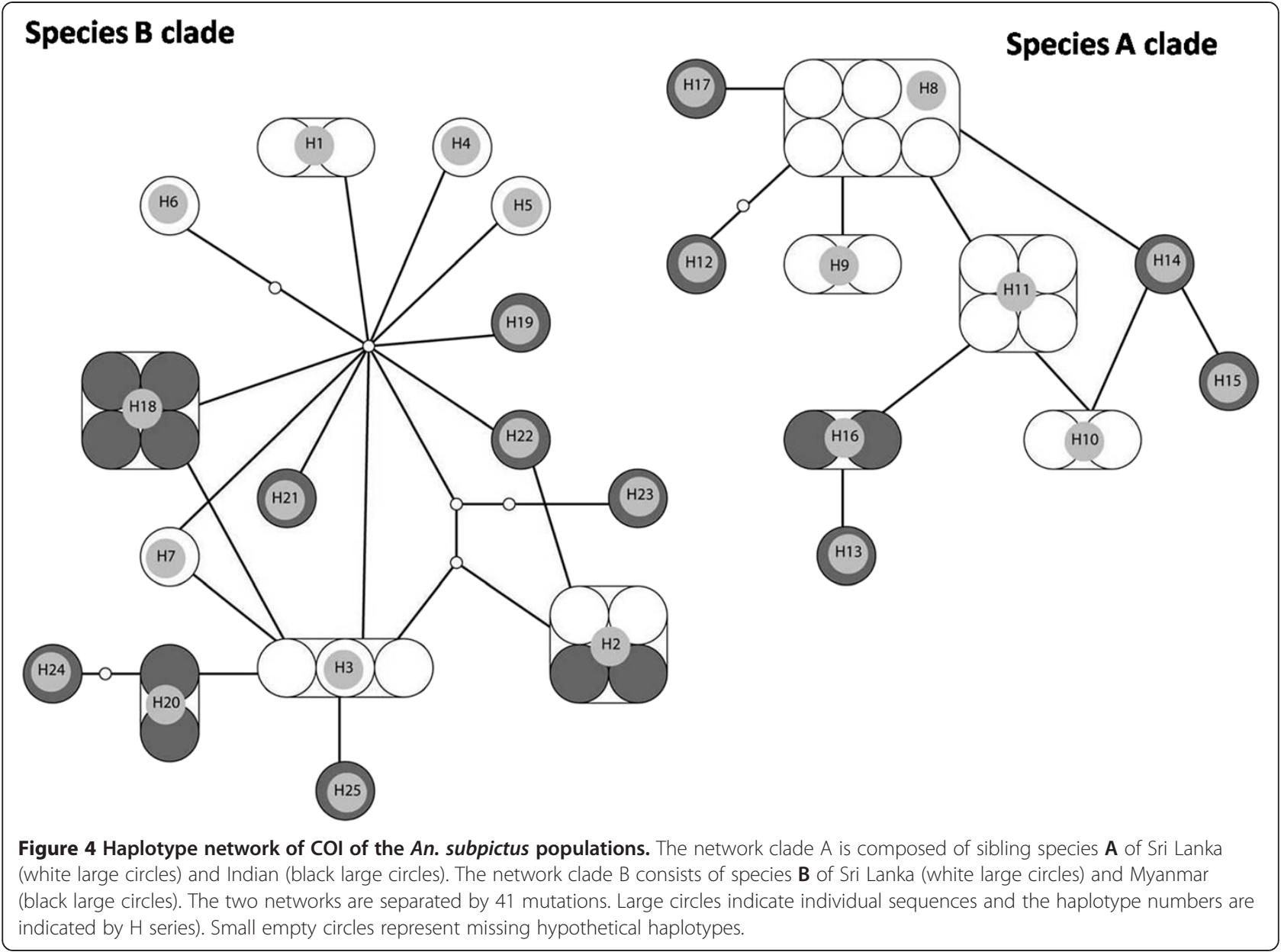

discriminate the members of the Subpictus complex in Sri Lanka. Morphological variation in the ornamentation of palpi and wing has also been reported previously among An. subpictus populations in India [36] and Sri Lanka [18]. Several other studies have also found that purported species diagnostic characters were in fact shared across taxa: wing spots in the Anopheles minimus complex [37]; spots on wings and proboscis in An. vagus and Anopheles limosus [38]; and palpi and wing in $A n$. sundaicus and An. subpictus in Timor-Leste [27]. This demonstrates the difficulties faced in identifying taxa based on morphological characters alone and the utility of molecular methods in identifying and distinguishing closely related Anopheles taxa. The diagnostic AS-PCR assay developed here is therefore expected to be very useful for the reliable identification of the two sibling species in Sri Lanka. The lack of population structure seen within species indicates that the method is likely to

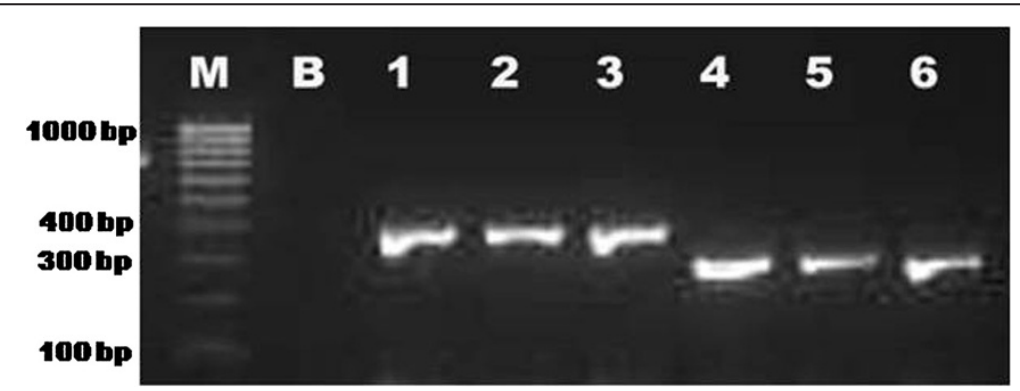

Figure 5 A 1.5\% agarose gel image showing the amplification of the diagnostic fragments for species A and B of the Subpictus complex in the ASPCR assay. M: 100 bp marker, B: control without DNA, 1-3: species B (B1 - B3); 4-6: species A (included morphologically identified species $A 1, C 1$ and D1). 
be widely applicable. The application of this assay in other countries where species A and B are prevalent should be evaluated before use, for example to verify that there is no cross-amplification from any other closely related species present e.g. An. sundaicus.

The phylogenetic analysis shows that species A of Sri Lanka and India are genetically divergent from other populations morphologically identified as $A n$. subpictus from other South and SE Asian countries including species B in Sri Lanka, India and Myanmar. A previous study from Sri Lanka based on sequences of the ITS2 and D3 domain of rDNA suggested that the majority of the specimens identified morphologically as An. subpictus species B in the east coast of Sri Lanka, and some identified elsewhere in SE Asia were genetically close to the well-known salinity-tolerant malaria vector An. sundaicus s.l. [15]. This relationship is supported here with both the ITS2 and CO1 markers revealing that $A n$. subpictus species A and $A n$. subpictus species B do not form a monophyletic clade, as is expected of members of the same species complex, and that they, An. sundaicus and An. vagus are all relatively closely related. Species A seems to be present only in the Indian subcontinent, mainly in Sri Lanka and India. Species B has a wider distribution than species A being present in Sri Lanka, India and Myanmar. Further studies are required to identify the number of distinct species within the An. subpictus complex, their phylogenetic relationships with other closely related species such as $A n$. sundaicus s.l. and An. vagus and to establish their accurate distributions in South and SE Asia.

A previous study that identified sibling species of the Subpictus complex based on morphological traits revealed that species $\mathrm{A}, \mathrm{C}$ and $\mathrm{D}$ (i.e. species $\mathrm{A}$ based on present molecular data) are found inland and breed predominantly in fresh water although they are also reported to breed in slightly brackish water with salinities of up to $4 \mathrm{ppt}$ [11]. However, species B in Sri Lanka can breed in both fresh and brackish water with salinity ranging from $0-30 \mathrm{ppt}$ [11]. In addition, the predominantly inland species (morphologically identified as $\mathrm{C}$ and $\mathrm{D}$ and inferred from molecular data herein to be species A) are more resistant to common insecticides than the coastal population of species $B$ [12]. This differential adaptation is likely caused by higher selection pressure on species $\mathrm{A}$ as decades of insecticide application to control malaria and for use in agriculture has mainly targeted the freshwaterinland areas in Sri Lanka. Population bottlenecks that arise due to insecticide application may explain the lower haplotype and nucleotide diversity of species A in Sri Lanka. Insecticide selection pressure has been reported as a factor underlying the pattern of genetic diversity in other mosquito species such as Aedes aegypti $[39,40]$.

The prevalence of species B at both inland and coastal localities indicates that it is not appropriate to classify populations of the Subpictus complex as strictly inland or coastal [41] especially in the Sri Lankan context. While the origin and spread of species B is yet to be established it should be noted that species B of Sri Lanka shared a haplotype with An. subpictus populations of Myanmar and that there was a lack of genetic differentiation within species B even across the large geographical distance from Sri Lanka to Myanmar. This lack of intraspecific differentiation could reflect a demographic history of these populations in which they have been derived recently and so have not accumulated genetic differences [17]. The ability of species B to flourish in brackish water may have facilitated the dispersal between Sri Lanka and Myanmar along a predominantly coastal route.

The molecular studies reported here concur with karyotypic studies which to date report only species A and B from Sri Lanka based on a single inversion in the $\mathrm{X}$-arm [8]. It would be of great interest to determine if this inversion difference corresponds to the molecular types of the ITS2 and COI markers as it is predicted from this study. The present study also showed that the molecular form of species A in Sri Lanka encompassed the full range of variation in number of egg ridges reported in species A, C and D in India. However, the possibility that additional species (or distinct chromosomal forms) of the An. subpictus complex exist in Sri Lanka, as reported in India [6], which cannot be detected by the molecular markers used here cannot be precluded. Although the loci used here, particularly ITS2, are generally able to detect very closely related species they can prove ineffective where speciation has been very recent [42] or is perhaps even ongoing, as in the $\mathrm{S}$ and $\mathrm{M}$ molecular forms of Anopheles gambiae $[43,44]$. To fully determine if there are species (or chromosomal forms) in the Subpictus complex in addition to species A and B described here, a coordinated study of polytene chromosomes, molecular markers, morphological characters and ecological characters would be required, ideally in both Sri Lanka and India.

\section{Conclusion}

Sri Lanka has now entered the pre-elimination phase of malaria with a low number of reported cases in recent times but the continuous monitoring of vector populations to identify the potential for malaria transmission and optimal vector control strategies is essential to prevent future outbreaks [45]. The presence of two or more uncharacterized sibling species of a species complex in a 
particular locality can conceal real disease transmission patterns and lead to sub-optimal vector control programmes. The present molecular characterization of the Subpictus complex in Sri Lanka shows the existence of two distinct sibling species namely species A and B and reports a DNA based diagnostic technique to distinguish them in Sri Lanka. Studies in coastal areas in the North Central Province [9] and inland areas of North Central and Eastern Provinces [3,4] of Sri Lanka indicate the involvement of An. subpictus in malaria transmission. These are therefore key areas for the application of this diagnostic AS-PCR assay to study species biology relevant to vector control and for vector incrimination studies.

\section{Additional files}

Additional file 1: Table S1. Sample collection sites and distribution of morphologically identified sibling species from Sri Lanka.

Additional file 2: Table S2. Summary of the genetic diversity estimate for An. subpictus population of Sri Lankan (SLK), India (IND) and Myanmar (MYN) based on $\mathrm{CO} 1$ sequence.

\section{Competing interests}

The authors declare that they have no competing interest.

\section{Authors' contribution}

SNS, CW and RR designed the study. PJJ, KG, NK and LBSP did field collections and identification. PK developed the modifications in the DNA extraction protocol. SNS did laboratory studies. SNS, DKS and PK did data analysis. SNS, CW and RR wrote the manuscript. DKS and PK contributed to the content of the manuscript. All authors read and approved the final manuscript.

\section{Acknowledgements}

The authors wish to acknowledge the following: The National Science Foundation of Sri Lanka (through the grant RG/BT/2011/04) and The Commonwealth Commission of United Kingdom (through the Academic Staff Fellowship Awarded to the first author) for financial assistance; The Director, National Anti-malaria Campaign for permission and Members of the Entomology Teams of the Anti-malaria Campaign of the districts of Hambantota and Kalmunai for field assistance.

\section{Author details}

${ }^{1}$ Department of Zoology, Faculty of Science, University of Jaffna, Jaffna 40000, Sri Lanka. ${ }^{2}$ Faculty of Life Sciences, University of Manchester, Oxford Road, Manchester M13 9PT, UK. ${ }^{3}$ Regional Medical Research Centre, NE region (ICMR), Dibrugarh 786001, Assam, India. ${ }^{4}$ Regional Office, Anti Malaria Campaign, Hambantota 82000, Sri Lanka.

Received: 24 May 2013 Accepted: 26 August 2013

Published: 30 August 2013

\section{References}

1. Chandra G, Bhattacharjee I, Chatterjee S: A review on Anopheles subpictus Grassi - a biological vector. Acta Trop 2010, 115:142-154.

2. Sinka ME, Bangs MJ, Manguin S, Chareonviriyaphap T, Patil AP, Temperley WH, Gething PW, Elyazar IRF, Kabaria CW, Harbach RE, Hay SI: The dominant Anopheles vectors of human malaria in the Asia-Pacific region: occurrence data, distribution maps and bionomic précis. Parasit Vectors 2011, 4:89.

3. Amerasinghe $\mathrm{PH}$, Amerasinghe FP, Wirtz RA, Indrajith NG, Somapala W, Pereira LR, Rathnayake AMC: Malaria transmission by Anopheles subpictus Grassi in a new irrigation project in Sri Lanka. J Med Entomol 1992, 29:577-581.
4. Ramasamy R, Ramasamy MS, Wijesundera DA, Wijesundera APS, Dewit I, Ranasinghe C, Srikrishnarajah KA, Wickramarantne C: High seasonal malaria transmission rates in the intermediate rainfall zone of Sri Lanka. Ann Trop Med Parasitol 1992, 86:591-600.

5. Surendran SN, Ramasamy R: The Anopheles culicifacies and An. subpictus complexes in Sri Lanka and their implications for malaria control in the country. Trop Med Health 2010, 38:1-11.

6. Suguna SG, Rathinam KG, Rajavel AR, Dhanda V: Morphological and chromosomal descriptions of new species of the Anopheles subpictus complex. Med Vet Entomol 1994, 8:88-94.

7. World Health Organization: Anopheline species complexes in South and South-east Asia. India: SEARO Technical Publication No. 57; 2007. (http:// apps.searo.who.int/pds_docs/B2406.pdf; accessed on 26 August, 2013).

8. Abhayawardana TA, Wijesuria SRE, Dilrukshi RRKC: Anopheles subpictus complex: distribution of sibling species in Sri Lanka. Indian J Malariol 1996, 33:53-60.

9. Abhayawardana TA, Wickramasinghe MB, Amerasinghe FP: Sibling species of Anopheles subpictus and their seasonal abundance in Chilaw area. Proc Sri Lanka Assoc Advan Sci 1999, 55:17.

10. Kannathasan S, Antonyrajan A, Srikrishnaraj KA, Karunaratne SHPP, Karunaweera ND, Surendran SN: Studies on prevalence of anopheline species and community perception of malaria in Jaffna district, Sri Lanka. Vector Borne Dis 2008, 45:231-239.

11. Surendran SN, Jude PJ, Ramasamy R: Variations in salinity tolerance of malaria vectors of the Anopheles subpictus complex in Sri Lanka and the implications for malaria transmission. Parasit Vectors 2011, 4:117.

12. Surendran SN, Jude PJ, Weerarathne TC, Karunaratne SHPP, Ramasamy R: Variations in susceptibility to common insecticides and resistance mechanisms among morphologically identified sibling species of the malaria vector Anopheles subpictus in Sri Lanka. Parasit Vectors 2012, 5:34.

13. Collins FH, Kamura L, Ranson HA, Vulule JM: Molecular entomology and prospects for malaria control. Bull World Health Organ 2000, 78:1412-1423.

14. Chatterjee SN, Chandra G: Role of Anopheles subpictus as a primary vector of malaria in an area in India. Jap J Trop Med Hyg 2000, 28:177-181.

15. Surendran SN, Singh OP, Jude PJ, Ramasamy R: Genetic evidence for malaria vectors of the Anopheles sundaicus complex in Sri Lanka with morphological characteristics attributed to Anopheles subpictus species B. Malar J 2010, 9:343.

16. Collins FH, Paskewitz SM: A review of the use of ribosomal DNA ( $r D N A)$ to differentiate among cryptic Anopheles species. Insect Mol Biol 1996, 5:1-9.

17. Walton C, Somboon P, O'Loughlin SM, Zhang S, Harbach RE, Linton Y-M, Chen B, Nolan K, Duong S, Fong M-Y, Vythilingam I, Mohammed ZD, Tring HD, Butlin RK: Genetic diversity and molecular identification of mosquito species in the Anopheles maculatus group using ITS2 region of rDNA. Infect Genet Evol 2007, 7(1):93-102.

18. Jude PJ, Ramasamy R, Surendran SN: Bionomic aspects of members of the Anopheles subpictus species complex in Sri Lanka. J Insect Sci 2013 (in print).

19. Christophers SR: The fauna of British India, including Ceylon and Burma. Diptera 4. Family Culicidae. Tribe Anopheline. London: Taylor \& Francis; 1933.

20. Amerasinghe FP: A guide to the identification of the anopheline mosquitoes (Diptera: Culicidae) of Sri Lanka -I Adult females. Cey J Sci (Biological Science) 1990, 21:1-16.

21. Amerasinghe FP: A guide to the identification of the anopheline mosquitoes (Diptera: Culicidae) of Sri Lanka -II Larvae. Cey J Sci (Biological Science) 1992, 22:1-13.

22. Sambrook J, Russell DW: Molecular Cloning: A Laboratory Manual (Vol. 1, $3^{r d}$ edn). Cold Spring Harbor, New York: Cold Spring Harbor Laboratory Press; 2001:6.1-6.12.

23. Simon C, Frati F, Beckenbach A, Crepsi B, Liu H, Flook P: Evolution, weighting and phylogenetic utility of mitochondrial gene sequences and a compilation of conserved polymerase chain reaction primers. Ann Entomol Soc Am 1994, 87:651-701.

24. Drummond AJ, Ashton B, Buxton S, Cheung M, Cooper A, Heled J, Kearse M, Moir R, Stones-Havas S, Sturrock S, Thierer T, Wilson A: Geneious version 4.8.5. http://www.geneious.com.

25. Tamura K, Peterson D, Peterson N, Stecher G, Nei M, Kumar S: MEGA5: molecular evolutionary genetics analysis using maximum likelihood, evolutionary distance, and maximum parsimony methods. Mol Biol Evol 2011, 28:2731-2739.

26. Felsenstein J: Confidence limits on phylogenies: an approach using the bootstrap. Evol 1985, 39:783-791. 
27. Cooper RD, Edstein MD, Frances SP, Beebe NW: Malaria vectors of Timor-Leste. Malar J 2010, I 9:40.

28. Librado P, Rozas J: DnaSP v5: a software for comprehensive analysis of DNA polymorphism data. Bioinformatics 2009, 25:1451-1452.

29. Los Alamos National Library: FindModel. http://www.hiv.lanl.gov/content/ sequence/findmodel/findmodel.html.

30. Excoffier L, Laval G, Schneider S: Arlequin (ver 3.0): an integrated software package for population genetics data analysis. Evol Bioinform Online 2005, $1: 47-50$.

31. Tamura K, Nei M: Estimation of the number of nucleotide substitutions in the control region of mitochondrial DNA in humans and chimpanzees. Mol Biol Evol 1993, 10:512-526.

32. Clement M, Posada D, Crandall K: TCS: a computer program to estimate gene genealogies. Mol Ecol 2000, 9:1657-1660.

33. Tyagi BK, Hiriyan J, Tewari SC, Ayanar K: Description of a new species, Anopheles pseudosundaicus (Diptera: Culicidae) from Kerala, India. Zootaxa 2009, 2219:49-60.

34. Kaura T, Sharma M, Chaudhry S, Chaudhry A: Sequence polymorphism in spacer ITS2 of the Anopheles (Cellia) subpictus Grassi (Diptera: Culicidae). Caryologia 2010, 63:124-133.

35. Kumar NP, Rajavel AR, Natarajan R, Jambulingam P: DNA barcodes can distinguish species of Indian mosquitoes (Diptera: Culicidae). J Med Entomol 2007, 44:1-7.

36. Kirti JS, Kaur J: Variations in ornamentation of wings and palpi of Anopheles (Cellia) subpictus Grassi collected from northwest India. J Vector Borne Dis 2004, 41:37-41.

37. Chen B, Harbach, Butlin RK: Molecular and morphological studies on the Anopheles minimus group of mosquitoes in southern China: taxonomic review, distribution and malaria vector status. Med Vet Entomol 2002, 16:253-265.

38. Zarowiecki M, Walton W, Torres E, McAlister E, Htun PT, Sumrande C, Sochanta T, Dinh TH, Ng LC, Linton Y: Pleistocene genetic connectivity in a widespread, open-habitat-adapted mosquito in the Indo-Oriental region. J Biogeogr 2011, 38:1422-1432.

39. Horrera F, Urdaneta L, Rivero J, Zoghbi N, Ruiz J, Carrasquel G, Martínez JA Pernalete M, Villegas P, Montoya A, Rubio_Palis Y, Rojas E: Population genetic structure of the dengue mosquito Aedes aegypti in Venezuela. Mem Inst Oswaldo Cruz, rio de janeiro 2006, 101:625-633.

40. Paupy C, Vazeille-Falcoz M, Mousson L, Rodhain F, Failloux AB: Aedes aegypti in Tahiti and Moorea (French Polynesia): isoenzyme differentiation in the mosquito population according to human population density. Am J Trop Med Hyg 2000, 62:217-224.

41. Chhilar JS, Chaudhry S: Phylogenetic analysis of Anopheles (Cellia) subpictus Grassi using rDNA-ITS2 Sequence. Proc Zool Soc 2012, 65:1-10.

42. Walton C, Handley JM, Kuvangkadilok C, Collins FH, Harbach RE, Baimai V, Butlin RK: Identification of five species of the Anopheles dirus complex from Thailand, using allele-specific polymerase chain reaction. Med Vet Entomol 1999, 13:24-32.

43. Costantini C, Ayala D, Guelbeogo WM, Pombi M, Some CY, Bassole $\mathrm{H}_{\text {, }}$ Ose K, Fotsing JM, Sagnon N, Fontenille D, Besansky NJ, Simard F: Living at the edge: biogeographic patterns of habitat segregation conform to speciation by niche expansion in Anopheles gambiae. BMC Ecol 2009, 9:16.

44. Caputo B, Santolamazza F, Vicente JL, Nwakanma DC, Jawara M, Palsson K, Jaenson T, White BJ, Mancini E, Petrarca V, Conway DJ, Besansky NJ, Pinto J, della Torre A: The "Far-West" of Anopheles gambiae molecular forms. PLOS ONE 2011, 6:e16415.

45. Abeyasinghe RR, Galappaththy GNL, Gueye SC, Kahn JG, Feachem RGA: Malaria control and elimination in Sri Lanka: Documenting progress and success factors in a conflict setting. PLOS ONE 2012, 7:e43162.

doi:10.1186/1475-2875-12-304

Cite this article as: Surendran et al: Molecular characterization and identification of members of the Anopheles subpictus complex in Sri Lanka. Malaria Journal 2013 12:304.

\section{Submit your next manuscript to BioMed Central and take full advantage of:}

- Convenient online submission

- Thorough peer review

- No space constraints or color figure charges

- Immediate publication on acceptance

- Inclusion in PubMed, CAS, Scopus and Google Scholar

- Research which is freely available for redistribution
C Biomed Central 